\title{
Negative Ion Formation in Electrospray Mass Spectrometry
}

\author{
Rolf F. Straub and Robert D. Voyksner \\ Analytical and Chemical Sciences, Research Triangle Institute, Research Triangle Park, North Carolina, USA
}

Negative ion electrospray (ES) operating on a single quadrupole mass spectrometer for the detection of low-molecular-weight molecules is discussed. The ES interface was operated at a positive cylindrical electrode potential to produce negative ions, and the results obtained were compared to the positive ion mode. As in the case of operation in the more common positive mode, negative ions with varying degrees of solvation and structurally relevant fragments can he obtained from a variety of solute species, including $\beta$-lactam antibiotics, aminoglycosides, aminocyclitols, tetracyclines, sulfonamides, nucleotides, peptides, and explosives. No fragmentation of parent species, except those from some labile explosives, was provided because low potential differences are applied between the capillary and the first skimmer, and electrical discharge is avoided in the gas phase. An increase in the capillary voltage resulted in collision-induced decomposition to produce structurally relevant fragment ions in both operation modes. An evaluation of representative chromatographic solvents indicated that 2-propanol added with oxygen in the ES bath gas is best suited to suppress electrical (corona) discharge phenomena in negative ion operation, whereas it aids in solution nebulization, desolvation, and transfer of ions in solution to the gas phase. For positive ion mode, no such precaution was necessary. Conditions that promote the formation of ions in solution usually improve ES response. Therefore, an increase in the solvent $\mathrm{pH}$ can increase the sensitivity in negative ion ES ionization. Negative ion ES offers the advantage of providing complementary structural information to help in the charactcrization of an unknown compound or to confirm a certain tentatively proposed structure. Nucleotides and explosives were best characterized in negative ion mode owing to the ease with which they form anions in solution, and they could be detected down to the 1-pg/ $\mu \mathrm{L}$ level. (J Am Snc Mass Spectrom 1993, 4, 578-587)

$\mathrm{E}$ lectrospray (ES) is a novel and powerful ionization technique, producing highly charged droplets from a solution. This nebulization technique has the possibility of numerous industrial applications $[1,2]$. Electrospray coupled with mass spectrometry began with the pioneering experiments of Dole et al. [3]. Simons et al. [4] first pointed out the possibility of application of ES for liquid chromatography/mass spectrometry (LC/MS), and Fenn and coworkers [5-10] have revolutionized mass spectrometry by demonstrating the ability to ionize high-molecularweight molecules at efficiencies that permit femtomole detection limits. The electrospray process can be characterized simply by four discrete steps: (1) nebulization and charging of the LC effluent, (2) desolvation, (3) ionization, and (4) extraction of ions into the mass spectrometer. The technique is limited to low LC flow rates of $1-10 \mu \mathrm{L} / \mathrm{min}$ without special modifications. The recently introduced ultrasonic mechanical vibra-

Address reprint requests to Robert D. Voyksner, Analytical and Chemical Sciences, Research Triangle Institute, P.O. Box 12194, Research Triangle Park, NC 27709-2194. tion nebulization-assisted ES (Ultraspray) device [11] and different approaches in source engineering [12], however, are changing the flow rate limits. The ion evaporation model of Iribarne and Thomson [13, 14], in which Coulombic explosion of rapidly evaporating liquid droplets of high charge density results in charged droplets with smaller sizes and in which this sequence continues until field-assisted ion evaporation occurs, is widely accepted. Gas-phase, multiply charged molecules can be formed from highly charged liquid droplets produced at atmospheric pressure.

Although, negative ions have been studied since the beginning of this evolving technique $[6,12]$, they have not received the attention given to positive ions. Therefore, advances in negative ion mode have not occurred as rapidly as those in positive ion electrospray mass spectrometry (ES/MS) experiments. Negative ion formation by ES ionization (ESI) has been demonstrated for a varicty of small molecules with acidic functionali ties, such as carboxylic, phosphoric, and sulfonic acid groups [15-19], and very recently for esters of boron acids [20]. Only a few negative ton LS mass spectra of polypeptides [21-23] and oligodeoxynucleotides [24] have been reported. 
One crucial reason for this is the fact that, for otherwise equivalent conditions, an electric (corona) discharge occurs, presumably caused by electrons emanating from the sharp edges of the ES needle held at a few thousand volts negative relative to a counterelectrode. A similar effect is also observed by grounding the ES needle and charging the surrounding cylindrical electrodes. For aqueous or highly conductive solutions, it becomes even more difficult to maintain stable $\mathrm{ES}$ in the case of negative polarities because generally higher voltage is necessary to $\mathrm{ES}$ the liquid. This situation makes negative ion mode ES/MS more difficult than ES/MS in the positive ion mode [25].

To improve negative ion operation in ES/MS, certain gases such as oxygen or sulfur hexafluroide can be coaxially added to the nebulized liquid in the ESI chamber $[6,26]$. These gases possess high electron affinity; thus, they act as electron scavengers and suppress corona discharge. The ability to inhibit such discharge improves stability, allows ES operation at higher voltages, and increases the lifetime of the goldplated glass capillary in the ES source. Chowdhury et al. [27] claimed that electric discharge can also be reduced by the use of sharpened ES capillary tips. This modification allows operation under a lower onset potential, thus permitting analyte ion formation before the outbreak of severe corona discharge. Another approach to combatting the problem of electric discharge from highly conductive solutions is to use chlorinated [28] or nonaqueous solvents [25].

Recently, Kebarle and co-workers $[29,30]$ made a detailed study of the physicochemical aspects of ESI. In examining fundamental aspects of the ESI phenomenon, several solvent properties, such as surface tension, conductivity, viscosity, and diclectric constant, were identified as important parameters in determining the success of the ES/MS process [31-33].

This report describes negative ion ES/MS operation on a single quadrupole mass spectrometer and compares the results with some positive ion operations. In a preliminary study, the ability of common chromatographic solvents to stabilize ES current and to promote intense analyte signals was compared. The target analytes chosen are representative antibiotics, nucleotides, tripeptides, and nitro group-containing explosives.

\section{Experimental}

\section{Materials}

Water was bidistilled and purified with a Milli-Q water system (Millipore Corp., Bedford, MA) prior to use. Methanol (MeOH), ethanol (EtOH), 2-propanol (IPA), acetone, tetrahydrofuran (THF), chloroform $\left(\mathrm{CHCl}_{3}\right)$, and acetonitrile $(\mathrm{MeCN})$ were of high-performance liquid chromatography (HPLC)/gas chromatography grade quality (Baxter Healthcare Corp., Muskegon, MI). 2-Methoxyethanol (MeEtOH) for HPLC (Aldrich Chemical Co., Milwaukee, WI) was glass distilled and filtered through $0.5-\mu \mathrm{m}$ filters. For $\mathrm{pH}$ and electrolyte adjustments, the mobile-phase additives acetic acid ( $\mathrm{HOAc}$ ), ammonium hydroxide $\left(\mathrm{NH}_{4} \mathrm{OH}\right.$ ), ammonium acetate, and magnesium chloride $\left(\mathrm{MgCl}_{2}\right)$ from Fisher Scientific (Rochester, NY) were used. Arginine and gramicidin $S$ from Bacillus brevis (Sigma Chemical Co., St. Louis, MO) were used as tuning compounds in positive ion ES/MS operation. For negative ion ES/MS operation the nucleotide adenosine $5^{\prime}$-monophosphate (Sigma) was used as the tuning compound and for all preliminary solvent studies. The $\beta$-lactam antibiotic penicillin G (potassium salt), ampicillin (anhydrous), amoxicillin, cloxacillin (sodium salt), and cephapirin (sodium salt) were from Sigma. The aminoglycoside and aminocyclitol antibiotics (herein referred to as aminoglycosides), streptomycin (sulfate salt), dihydrostreptomycin (sulfate salt), neomycin (sulfate salt), gentamicin (sulfate salt), hygromycin B (approximately 85\%) and spectinomycin (di- $\mathrm{HCl}$ adduct) were also from Sigma. The three tetracycline antibiotics chlorotetracycline (CTC), oxytetracycline (OTC), and tetracycline (TC) were received from the U.S. Food and Drug Administration (Beltsville, MD). The sulfonamide standards sulfachloropyridine, sulfadimethoxine, sulfamerazine, sulfamethazine, sulfadiazine, sulfamethoxazole, and sulfamethizole were from Sigma. The nucleotides and deoxynucleotides adenosine $5^{\prime}$ monophosphate, 2'-deoxyadenosine $3^{\prime}$-monophosphate, 2'-deoxycytidine $3^{\prime}$-monophosphate, guanosine 3'-monophosphate, 2'-deoxyguanosine 3-monophosphate, inosine $5^{\prime}$-monophosphate, and thymidine $3^{\prime}$ monophosphate were from Sigma and from the $\mathrm{Na}$ tional Institute of Environmental Health Sciences (Research Triangle Park, NC). The composition of the tripeptides was aspartic acid (D), tryptophan (W), glycine (G), and argine (R). Seven different tripeptides, abbreviated as DWD, DRD, WGW, GWG, WRW, GRG, and RWR, were received from Professor B. Erickson from the University of North Carolina (Chapel Hill, NC). The pure explosive components studied included 2,4,6-N-tetranitro- $N$-methylaniline (tetryl); 1,3,5-trinitro-1,3,5-triaza-cyclohexane (RDX); 1,3,5,7-tetranitro1,3,5,7-tetracyclooctane (HMX); pentaerythritol tetranitrate (PETN); and ammonium picrate (Department of Isotope Research, Weizman Institute of Science, Rehovot, Israel, and North Carolina State Bureau of Investigation, Raleigh, NC).

\section{Instrumentation}

For flow infusion experiments, a Sage 341 micro syringe pump (Sage Instruments, Division of Orion Research Inc., Boston, MA) and a $50-\mu \mathrm{L}$ PS C-160 FN syringe for a Waters U6K injector (Dynatech Precision Sampling Corp., Baton Rouge, LA) were utilized. The eluents used in the flow injection of antibiotics were delivered by an ISCO $100 \mathrm{D}$ syringe pump/pump controller, model 174262 (Isco Inc., Lincoln, NE). The 
samples were injected with an Actuator, model 732 with a 5- $\mu \mathrm{L}$ sample loop (Alcott Chromatography Inc., Norcross, GA).

An Analytica HPLC/ES/MS interface, model 101737, with autotune capability, was connected to a Hewlett-Packard Engine, model HP 5989A, single quadrupole mass spectrometer (Hewlett-Packard Co., Palo Alto, CA). For instrument control and data acquisition, a Hewlett-Packard HP Vectra 80486-33 EISA personal computer/MS-DOS Chemstation software versions $\mathrm{M} 2.43$ and $\mathrm{M} 3.04$ were utilized. Sample $\mathrm{pH}$ was measured with a Cole Parmer $\mathrm{pH}$ meter (Cole Parmer Instrument Corp., Chicago, IL) and an Orion Ross combination pH 81-15 electrode (Orion Research) at $20^{\circ} \mathrm{C}$.

For the flow injection and flow infusion experiments, the ES interface was autotuned with a arginine/gramicidin $\mathrm{S}$ mixture $(50 \mathrm{ng} / \mu \mathrm{L}$ each) in $\mathrm{MeOH} /$ water (1:1) for positive ion operation. In the ES interface, model 101737, for the HP 5989A instrument, the hypodermic needle is grounded, and charging occurs by keeping the cylindrical electrode $\left(V_{1}\right)$ at approximately -3.4 to $-3.7 \mathrm{kV}$, the endplate $\left(V_{2}\right)$ at $-3.8 \mathrm{kV}$, and the capillary $\left(V_{3}\right)$ at $-4.3 \mathrm{kV}$. Best results were obtained with skimmer $(S)$ and lens voltages $(L)$ of $S_{1}=27 \mathrm{~V} ; L_{1}=25 \mathrm{~V}, S_{2}=7 \mathrm{~V}, L_{2}=4 \mathrm{~V}$; and $L_{3}=-53 \mathrm{~V}$. The actual setting was dependent on the electrode potentials $V_{1}, V_{2}$, and $V_{3}$ and varied within a range $\pm 1-10 \mathrm{~V}$. The capillary/skimmer or collision-induced decomposition (CID) potential difference was varied between 40 and $400 \mathrm{~V}$. A solution of $50 \mathrm{ng} / \mu \mathrm{L}$ adenosine $5^{\prime}$-monophosphate in IPA/water (8:2), with an addition of $0.5 \%(\mathrm{v} / \mathrm{v})$ $\mathrm{NH}_{4} \mathrm{OH}$ for $\mathrm{pH}$ adjustment was used to tune the ES source in negative ion ES/MS operation. To maintain a stable ES current and to prevent a breakdown to discharge, oxygen, as electron scavenger gas, was coaxially added to the nebulized solution. Lower electrode potentials $\left(V_{1}=2.8 \mathrm{kV} ; V_{2}=2.9 \mathrm{kV} ;\right.$ and $V_{3}=3.0$ $\mathrm{kV})$ than in positive ion ES/MS operation were applied. Best results were obtained with $S_{1}=-36 \mathrm{~V}$; $L_{1}=-30 \mathrm{~V} ; S_{1}=-16 \mathrm{~V} ; L_{2}=-16 \mathrm{~V} ;$ and $L_{3}=36$ v.

The three-layered ES needle used consisted of a $50-\mu \mathrm{m}$ i.d. stainless steel inner tube to deliver solvent and a $125-\mu \mathrm{m}$ i.d. second-layer tube to deliver an additional solvent as a sheath flow to erhance ES operation, especially when using high percentages of water. The third and outer tube was used to coaxially add gas to aid in nebulization. In negative ion operation, oxygen was generally used as an electron scavenger gas. Figure 1 presents the three-layered ES needle. Preliminary experiments in negative ion ES operation produced more stable currents when IPA was directly mixed with the sample solution rather than added as sheath flow; but for certain negative ion ES/MS applications, the infusion of a sheath flow is still the best compromise, especially when the added solvent stabilizes ES current and improves ES re-

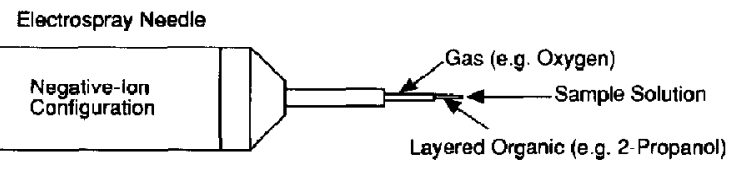

Figure 1. The three-layered ES needle used in negative ion operation configuration for successful nebulization and ionization. The inner needle delivers the sample solution; with the middle tube, a sheath flow can be added; and the largest tube is used to coaxially introduce gas to aid in nebulization.

sponse, and no direct mixing with the analyte solution is possible or recommended.

\section{Results and Discussion}

\section{Effect of Chromatographic Solvents on the Generation of Negative Ions in the Electrospray Ionization Process}

There is limited information about the effect that chromatographic solvents have on the generation of negative ions in the ESI process. So far, there are only a few investigations completed concerning solvent effects in negative ion ESI $[4,25,28]$. The major attribute of a proper solvent is the ability to suppress electric discharge, but it should also completely dissolve the analyte and be suitable for LC if it is applied as a mobile-phase additive. The solvent can also be added as a sheath flow through the second tube of the ES probe (see Figure 1). This dilutes the analytes and does not always stabilize the ES current. The stability of the ES current depends considerably on the kind of eluent mixed and on the flow rate of infusion.

All experimental parameters, including temperatures, nitrogen and oxygen flow rates, position of the ES needle, infusion flow rates, analyte concentration, and voltage settings, were held constant during the test runs for the data presented in Table 1 and Figure 2 . The test analyte was adenosine 5 -monophosphate (AMP) dissolved in $1 \% \mathrm{MeOH}, 0.5 \% \mathrm{NH}_{4} \mathrm{OH}$, and 98.5\% of each of the tested solvents. After every medsurement, the voltages on the cylindrical electrode were increased to find the onset of corona discharge. The onset of discharge was arbitrarily defined as the

Table 1. Comparison of $[\mathrm{M}-\mathrm{H}]^{-}$ion response of adenosine 5' monophospl late' in different sulvents

\begin{tabular}{lc}
\hline Solvent & Relative response (\%) \\
\hline \hline Methanal & 59 \\
Ethanol & 5 \\
2-Propanol & 100 \\
2-Methoxyethanol & 70 \\
Acetone & 15 \\
Tetrahyrdrofuran & 6 \\
Chloroform & 43 \\
Acetonitrile & 9 \\
\hline
\end{tabular}

${ }^{a} c=37 \mathrm{ng} / \mu \mathrm{L} ; 0.5 \%(\mathrm{v} / \mathrm{v})$ ammonium hydroxide was added to all solvents to adjust the $\mathrm{pH}$. 

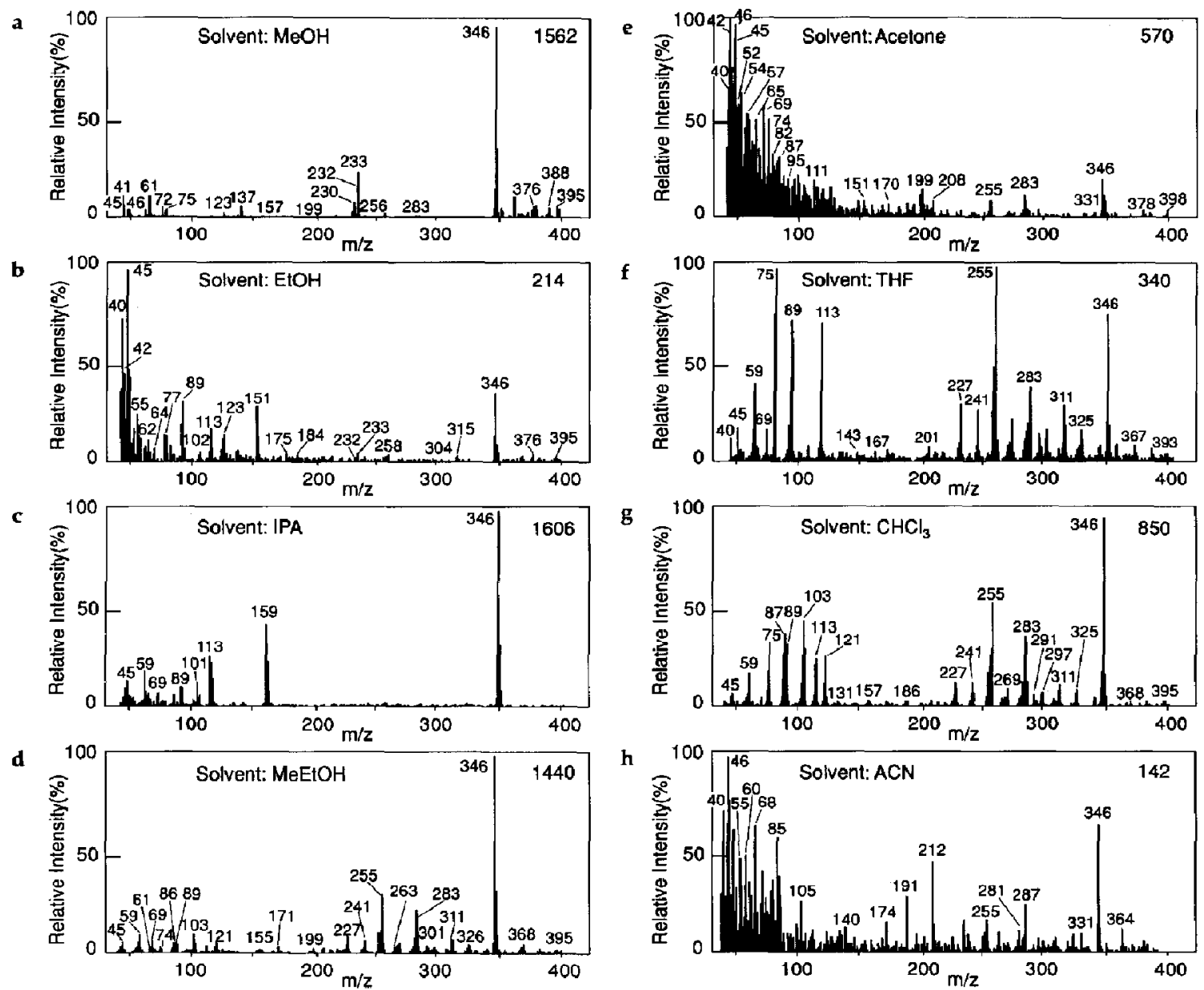

Figure 2. Negative ion ES mass spectra of $37 \mathrm{ng}$ of AMP [molecular weight (MW) 347] in different solvents at a capillary potential of $-100 \mathrm{~V}$. $\mathrm{NH}_{4} \mathrm{OH} 0.5 \%(\mathrm{v} / \mathrm{v})$ was added to all solvents to adjust the $\mathrm{pH}$. Number at top right indicates ion counts.

ES capillary voltage that yielded a current above 50 $\mu \mathrm{A}$ (the maximum current that can be read out on the ammeter). Normally, a capillary voltage of $V_{3}=2980$ $V$, end-plate voltage of $V_{2}=2910 \mathrm{~V}$, and a cylinder voltage of $V_{1}=2740 \vee$ were used for each analyte/solvent combination without any risk of a breakdown to discharge. An increase in the potential of the cylindrical electrode would eventually generate a very unstable signal, followed by a large increase in the total current, even when oxygen was added as the electron scavenger gas.

Stable ion currents with discharge-onset voltages in the range $4.5-5 \mathrm{kV}$ were observed with $\mathrm{MeOH}$, IPA, and MeEtOH. Moderate stability and lower discharge onset in the range 3-4 kV were observed with $\mathrm{CHCl}_{3}$, acetone, and MeCN. The infusion of EtOH and THF produced a very unstable ES current, and the danger of a corona discharge was already given in the range $2.9-3.5 \mathrm{kV}$. Use of pure water did not produce a stable signal and was therefore not considered for this com- parison. Because electric discharge in the ES source can etch the gold-plated capillary, these preliminary experiments were not pursued further. Instead, the relative response of the $[\mathrm{M}-\mathrm{H}]^{-}$ion of AMP at $m / z 346$ in all tested solvents was listed for a capillary voltage of $100 \mathrm{~V}$ (Table 1). The alcohols IPA, MeETOH, and $\mathrm{MeOH}$ produced stable electron currents and intense signals. Lower signal intensities were observed with $\mathrm{CHCl}_{3}$, acetone, and MeCN. As before, EtOH and THF produced only very weak and rather unstable signals. Figure 2 shows the ES spectra of $37 \mathrm{ng} / \mu \mathrm{L}$ AMP in all eight solvents at a capillary potential of $-100 \mathrm{~V}$. The use of IPA leads to the most abundant $[\mathrm{M}-\mathrm{H}]^{-}$ion with few background ions. Therefore, IPA is an ideal choice as a mobile-phase additive in negative ion ES/MS operation. Also, AMP dissolved in $\mathrm{MeOH}$ or MeEtOH exhibits an abundant $[\mathrm{M}-\mathrm{H}]^{-}$ion, a few fragment ions, and a low background. Less suitable solvents, such as $\mathrm{CHCl}_{3}$, acetone, and $\mathrm{MeCN}$, produce a higher background throughout the whole mass range 
but, in particular, at lower mass-to-charge ratios. The nucleotide dissolved in EtOH or THF yielded a lowabundance $[\mathrm{M}-\mathrm{H}]^{-}$ion and comparatively abundant background ions.

\section{Antibiotics and Sulfonamide Drugs}

Different veterinary drugs, such as $\beta$-lactam, aminoglycoside, aminocyclitol, and tetracycline antibiotics, and synthetic sulfonamides were investigated for negative ion operation. The results were compared to those from corresponding positive ion ES/MS measurements. Penicillins contain a 6-aminopenicillanic acid nucleus, and cephalosporins possess a 7 -amino cephalosporinic acid nucleus [34]. Owing to this carboxylic group, the penicillins are suitable for negative ion ES/MS detection. In contrast to this, aminoglycosides are highly functionalized cyclohexane aglycone glucosidically linked to amino or neutral sugar residues [35]. These antibiotics lack acidic protons, limiting the formation of molecular anions in solution. This can prevent $[\mathrm{M}-\mathrm{H}]^{-}$ions from being formed in the ESI process. Owing to the dissociable protons in the polyhydronaphthacene nucleus of tetracyclines, the formation of anions is possible without partial destruction of the molecule. The acidic sulfonamide drugs represent a very promising class for negative ion ES/MS operation because anions can be easily formed in alkaline media.

Negative ion ES mass spectra of selected antibiotic standards are briefly discussed in this section, without showing all appropriate mass spectra. A concentration of $100 \mathrm{ng} / \mu \mathrm{L}$ of each drug in IPA/water (1:1) or $\mathrm{MeOH} /$ water (1:1) was infused into the ES interface. To adjust the $\mathrm{pH}, 0.5 \%(\mathrm{v} / \mathrm{v}) \mathrm{NH}_{4} \mathrm{OH}$ or $1 \%(\mathrm{v} / \mathrm{v})$ HOAC was added to the solutions. It was possible to record CID spectra generated in the ES transport region between the capillary and first skimmer by controlling the potential difference between these two elements. Al increased potential differences, all ions are accelerated in the high-pressure supersonic expansion region, resulting in collisional activation. As the potential difference was increased, enough internal energy could be imparted to the molecules to produce the multiple bond cleavage necessary for structure elucidation. This method of collisional activation has been shown to introduce greater than $16 \mathrm{eV}$ of internal energy into the molecule, yielding extensive fragmentation with less than $20 \%$ loss in ion current [36].

Figure 3 presents the negative and positive ion ES spectra of cephapirin at a capillary/skimmer potential of $-120 \mathrm{~V}$ and $+120 \mathrm{~V}$, respectively. Lower CID energies normally gave rise to only the $[\mathrm{M}-\mathrm{H}]^{-}$ion and very few structurally relevant fragments. Capillary/skimmer potentials exceeding $-200 \mathrm{~V}$ always produce more fragmentations but also add considerably more background noise without contributing additional structural information. The fragmentations
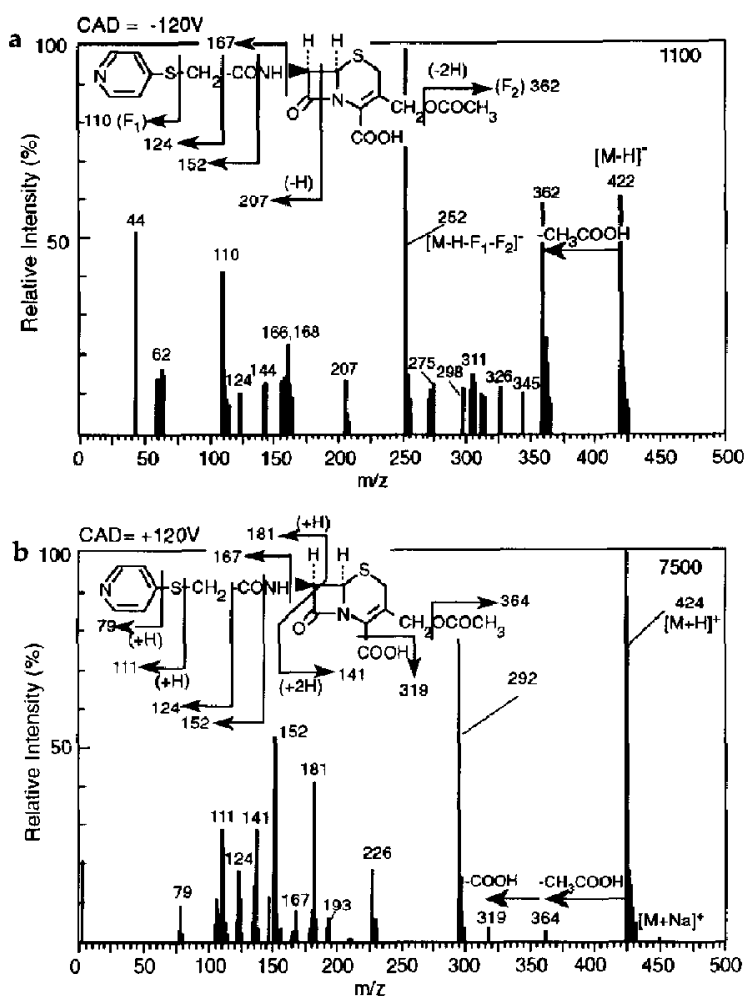

Figure 3. Comparison of negative and positive ion ES/MS of $100 \mathrm{ng} / \mu \mathrm{L}$ cephapirin (MW 423). (a) Capillary potential $-120 \mathrm{~V}$ : solvent, IPA/water (1:1) with $0.5 \%(\mathrm{v} / \mathrm{v}) \mathrm{NH}_{4} \mathrm{OH}$, and (b) capillary potential $+120 \mathrm{~V}$; solvent, $\mathrm{MeOH} /$ water $(1: 1)$. Number at top right indicates ion counts.

seen in the mass spectrum in Figure 3a resulted mainly from a loss of $\mathrm{CH}_{3} \mathrm{COOH}$ to give an ion of $\mathrm{m} / z 362$ and consecutive cleavages of the amide moiety to give products at $m / z 110,124,152$, and 167 . The most abundant ion peak at $m / z 252$ is tentatively attributed to the cleavage product $\left[\mathrm{M}-\mathrm{H}-\mathrm{F}_{1}-\mathrm{F}_{2}\right]^{-}$. The ion at $m / z 207$ can be formed by either cleavage of the $\beta$-lactam ring or by loss of $\mathrm{COOH}$ from the $m / z 252$ ion. The positive ion ES spectrum (Figure $3 \mathrm{~b}$ ) shows formation of a low-abundance sodium adduct ion at $m / z 446$ and an abundant $[\mathrm{M}+\mathrm{H}]^{+}$ion at $m / z 424$. Low-abundance ions at $m / z 364$ and 319 were tentatively identified as resulting from a loss of $\mathrm{CH}_{3} \mathrm{COOH}$ and a combined loss of $\mathrm{CH}_{3} \mathrm{COOH}$ and $\mathrm{COOH}$ from the $[\mathrm{M}-\mathrm{H}]^{-}$ion. Lower molecular weight fragments at $m / z 79,111,124,152$, and 167 are from consecutive cleavages of the amide moiety. The fragment ions at $m / z 141$ and 181 are tentatively identified as two cleavage products of the $\beta$-lactam ring.

The negative ion ES mass spectrum of the aminocyclitol hygromycin $\mathrm{B}$ exhibited an $[\mathrm{M}-\mathrm{H}]^{-}$ion at $\mathrm{m} / \mathrm{z}$ 526 and a glycosylate bond cleavage product at $m / z$ 337 as major identifiable ions at a capillary potential of $-100 \mathrm{~V}$. Lower capillary voltages favor the formation of the $[\mathrm{M}-\mathrm{H}]^{-}$ion, and higher capillary voltages 
produce more fragmentations, giving ions with massto-charge ratios smaller than 100 as well as a water adduct $\left[\mathrm{M}+2 \mathrm{H}_{2} \mathrm{O}-\mathrm{H}\right]^{-}$ion at $m / z 562$. Positive ion ES/MS operation at a capillary voltage of $+200 \mathrm{~V}$ produces an abundance $[\mathrm{M}+\mathrm{H}]^{+}$ion at $m / z 528$ and tragment ions at $m / z 352,339,264$, and 177 . The cleavage is mairly along the glycosylate bonds. The low-abundance ions at $m / z 191$ and 145 are charged sugar residues. The ion at $m / z 159$ represents the free cyclohexane aglycone moiety (spectra not shown). An HPLC separation with ion-spray mass spectrometry detection of five aminoglycosides was recently reported [37].

The tetracycline antibiotics exhibit an abundant [M $-\mathrm{H}]^{-}$ion and no fragment ions at low capillary voltages. An increase in the capillary voltage produces additional simple fragments from the loss of functional groups, such as $\mathrm{N}\left(\mathrm{CH}_{3}\right)_{2}$ and $\mathrm{CON}$ (or $\mathrm{Cl}$ for $\mathrm{CTC}$ ), from the $[\mathrm{M}-\mathrm{H}]^{-}$ion. No cleavage of the polyhydronaphthacene nucleus was observed for any of the three tested tetracycline antibiotics CTC, OTC, and TC in the negative ion ES/MS operation. The positive ion ES mass spectrum of TC at a capillary voltage of $+200 \mathrm{~V}$ shows an abundant $[\mathrm{M}+\mathrm{H}]^{\dagger}$ ion at $m / z$ 445, an $[\mathrm{M}+\mathrm{H}-\mathrm{OH}]^{+}$ion at $m / z 428$, an abundant ion at $m / z 410$, and a low-abundance fragment ion at $m / z$ 392. The high amount of low-molecular-weight fragments points to a partial destruction of the polyhydronaphthacene nucleus at higher $\mathrm{CID}$ energies. When lower capillary/skimmer potentials in the range 40-100 V were used, an abundant molecular ion but little fragmentation of the CTC, OTC, or TC molecule were found (spectra not shown).

The sulfonamides (SAs) showed an abundant [M $\mathrm{H}]^{-}$ion and only a few structurally relevant fragment ions, mostly formed by cleavages adjacent to the SA functional group. For example, sulfamethizole produces an abundant $[\mathrm{M}-\mathrm{H}]^{-}$ion at $m / z 269$, an $\left[\mathrm{H}_{2} \mathrm{NC}_{6} \mathrm{H}_{4} \mathrm{SO}_{2}+\mathrm{H}_{2} \mathrm{O}-\mathrm{H}\right]^{+}$ion at $m / z 195$, and the two $\mathrm{S}-\mathrm{N}$ bond cleavage products at $\mathrm{m} / z 155$ and 113. Lower capillary voltages form an abundant $[\mathrm{M}-\mathrm{H}]^{-}$ion without any fragments that are relevant for structure elucidation (spectra not shown). The ions at $m / z 92\left(\left[\mathrm{H}_{2} \mathrm{NC}_{6} \mathrm{H}_{4}\right]^{+}\right), m / z 108\left(\left[\mathrm{H}_{2} \mathrm{NC}_{6} \mathrm{H}_{4} \mathrm{O}\right]^{1}\right)$, and $m / z 156\left(\left[\mathrm{H}_{2} \mathrm{NC}_{6} \mathrm{H}_{4} \mathrm{SO}_{2}\right]^{+}\right)$are common to all tested SAs in positive ion ES/MS. These fragments can be valuable for confirmatory purposes or when searching for SAs as a class. Raising the capillary/skimmer voltage to $+180 \mathrm{~V}$ also provides a specific fragment ion for sulfamethizole at $\mathrm{m} / \mathrm{z} \quad 116$ attributed to $\left[\mathrm{H}_{3} \mathrm{NC}_{2} \mathrm{H}_{3} \mathrm{~N}_{2} \mathrm{~S}\right]^{+}$. Thus, higher capillary/skimmer voltages can provide relatively abundant and specific ions owing to the formation of an $\left[\mathrm{RNH}_{3}\right]^{+}$ion (where $\mathrm{R}$ represents the different amine moieties in the SAs). A comprehensive investigation of positive ion ES/MS of SAs was recently published by Perkins et al. [38].

Table 2 lists the sum of the major ions of all four tested drug classes in the positive and negative ion ES operation mode. The average relative response of posi- tive ion ES spectra was arbitrarily set to $100 \%$. $\beta$ Lactam antibiotics show about fourfold, aminoglycosides almost 100-fold, tetracyclines twelvefold, and SAs about threefold less intense signals in negative ion ES operation. The high-energy dynode in the mass spectrometer detector, applied in positive ion ES/MS operation to gain sensitivity, does not produce the same enhancement in negative ion operation. Therefore, overall negative ion operation appears less sensitive than positive ion detection on the basis of multiple efficiency for the determination of $\beta$-lactams and SAs. The lower responses of aminoglycosides and tetracyclines in negative ion detection were more than could be attributed to detection efficiency. The ability of these compounds to form stable anions must be considered.

Solution chemistry plays a major role in negative ion sensitivity, as is commonly described in positive ion ES/MS detection. Table 3 lists the average relative responses of the four tested drug classes. It was found that at higher solvent $\mathrm{pH}$, better ion currents were obtained from all tested standards [39, 40]. Typically, $\mathrm{pH} 10$, achieved through the addition of $50 \mathrm{mM}$ $\mathrm{NH}_{4} \mathrm{OH}$, resulted in more than doubled ES responses from $[\mathrm{M}-\mathrm{H}]^{-}$ions compared with the "nonbuffered" solution at $\mathrm{pH} 7$. No signals were observed in acidic media ( $\mathrm{pH}$ 3) obtained by adding $1 \%$ of HOAc. These observations are consistent with the formation of anions in solution prior to ion evaporation to achieve the optimal ES sensitivity.

\section{Nucleotides}

ES/MS is well suited for the detection of individual nucleotides. The ES detection was most sensitive in the negative ion detection mode owing to the ease of forming a stable phosphate anion. The ES mass spectrum in IPA/water (1:1) with $0.5 \% \mathrm{NH}_{4} \mathrm{OH}$ consisted of only an $[\mathrm{M}-\mathrm{H}]^{-}$ion at low capillary/skimmer potential difference. For example, AMP only showed a $[\mathrm{M}-\mathrm{H}]^{-}$ion at $m / z \quad 346$ al a capillary/skimmer voltage of $-80 \mathrm{~V}$. A capillary/skimmer potential difference of $60-80 \mathrm{~V}$ in IPA/water (1:1) resulted in the formation of the $[\mathrm{M}-\mathrm{H}]^{-}$ions for all of the other nucleosides evaluated. As the capillary/skimmer potential difference is increased, CID spectra can be generated to identify the specific nucleotide. Figure 4 shows the added structural information obtained for

Table 2. Comparison between negative and positive ion ES/MS sensitivity for selected classes of drugs

\begin{tabular}{lc}
\hline Drug class & Relative average response $(\%)^{\mathrm{a}}$ \\
\hline \hline$\beta$-Lactam & 24 \\
Aminoglycoside & 1 \\
Tetracycline & 8 \\
Sulfonamide & 38
\end{tabular}

The relative average response for the drugs in positive ion ES AMS operation was arbitrarily set to $100 \%$. 
Table 3. Comparison of electrospray negative ion sensitivity for selected classes of drugs at different $\mathrm{pH}$

\begin{tabular}{llrr}
\hline & \multicolumn{3}{c}{ Relative average response (\%) } \\
\cline { 2 - 4 } Drug class & $\mathrm{pH} \mathrm{3}$ & $\mathrm{pH} \mathrm{7}$ & $\mathrm{pH} \mathrm{10}$ \\
\hline \hline$\beta$-Lactam & 0.1 & 10 & 11 \\
Aminoglycoside & 0 & 1 & 3 \\
Tetracycline & 0.1 & 17 & 35 \\
Sulfonamide & 0.2 & 25 & 100 \\
\hline
\end{tabular}

AMP at a capillary/skimmer potential difference of $-280 \mathrm{~V}$. The added structural information obtained from the CID mass spectrum in Figure 4 provides the capability to identify modification of the base or sugar, as well as to determine the molecular weight of the nucleotide. Table 4 summarizes the fragmentation pathway for the seven nucleotides. The CID spectra can be useful in identifying a deoxyribose versus ribose nucleotide by the presence of an ion at $m / z 195$ for deoxyribose or $m / z 211$ for the ribonucleotide (fragmentation path B). Furthermore, the modified base $R$ can be easily identified through the detection of CID products that formed through fragmentation path $\mathrm{A}$. The ions at $m / z 79\left(\left[\mathrm{PO}_{3}\right]^{-}\right)$and $m / z 97\left(\left[\mathrm{H}_{2} \mathrm{PO}_{4}\right]^{-}\right)$ were common product ions for all nucleotides evaluated. Finally, CID products where the charge remains on the nucleoside, versus the phosphate, were observed for several nucleotides (fragmentation path $C$ ). Guanosine $3^{\prime}$-monophosphate exhibited the most intense CID product that followed path $\mathrm{C}$.

The CID efficiency in the ES transport region is quite high compared with tandem mass spectrometry techniques [34]. The CID efficiency for forming product ions and the overall transmission of ions through the CID region often exceed 80\% (Figure 5). At low capillary/skimmer voltages, the $[\mathrm{M}-\mathrm{H}]^{-}$ion transmission is optimized at approximately $120-\mathrm{V}$ potential difference. As the potential difference between the capillary and skimmer increases, product ion intensity

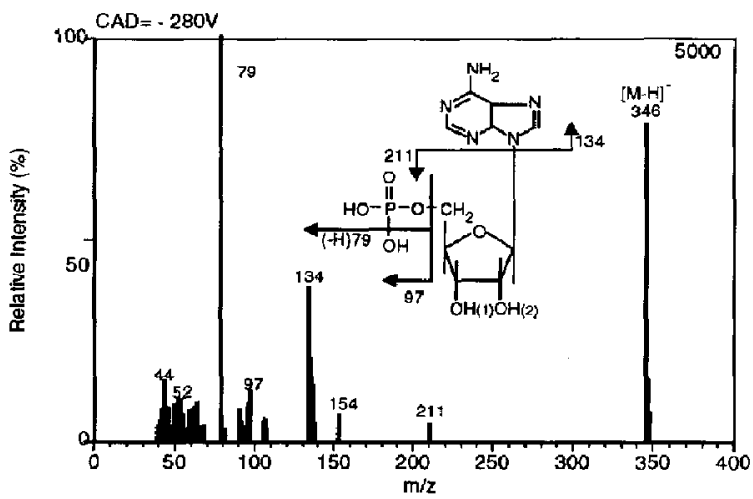

Figure 4. Electrospray negative ion mass spectra of AMP (MW $347)$ in IPA/water (1:1) with $0.5 \%(v / v) \mathrm{NH}_{4} \mathrm{OH}$. Capillary potential $+280 \mathrm{~V}$; CID product ions detected are indicative of structure.
Table 4. Fragmentation of selected nucleotides at a capillary/skimmer potential difference of $280 \mathrm{~V}$
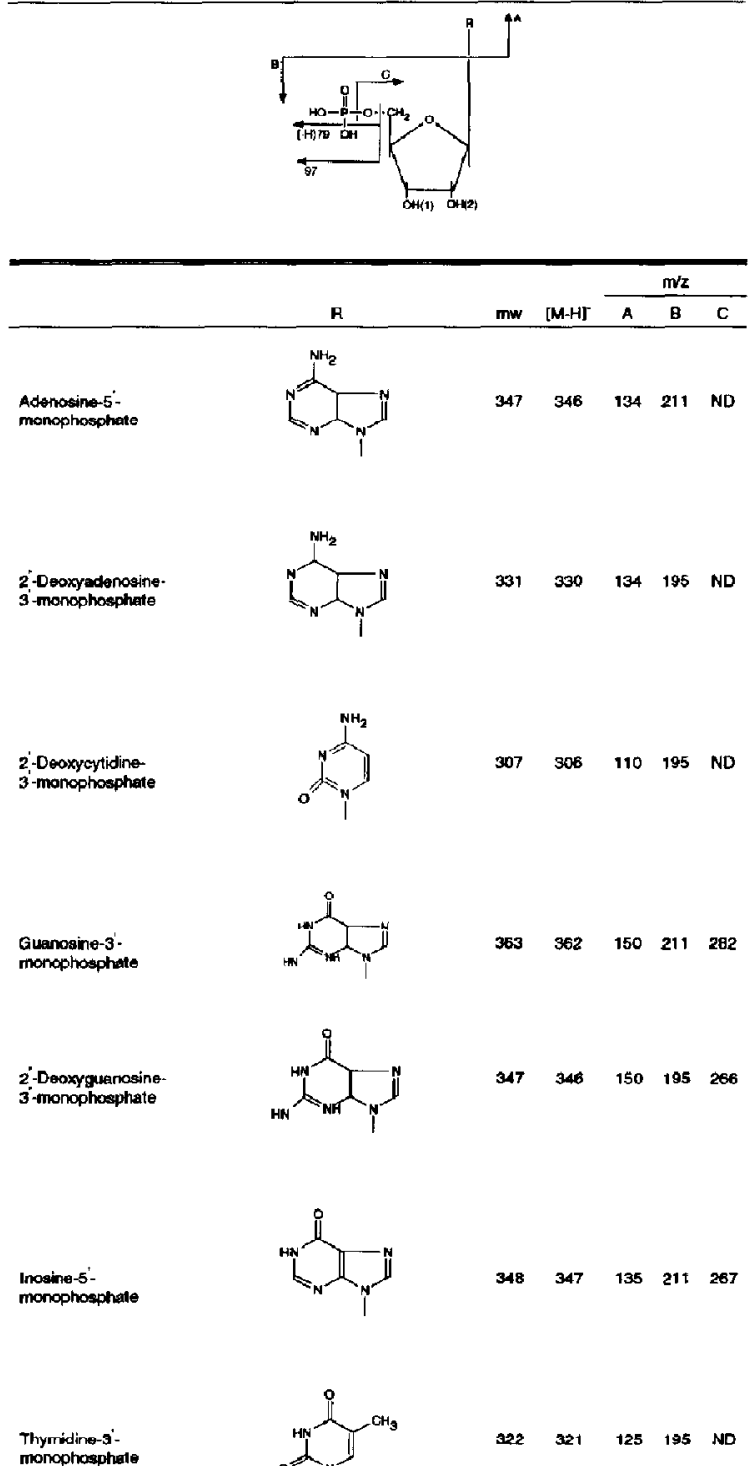<smiles>Cc1cn(C)c(=O)[nH]c1=O</smiles>

$22321 \quad 123 \quad 195 \quad N D$

Remarks: $3^{\prime}$-Monophosphate have $\mathrm{OH}$ replaced with $\mathrm{H}_{2} \mathrm{PO}_{4}$ (5' position now is OH). 2'-Deoxy and thymidine have $\mathrm{OH}$ replaced by H. $\mathbf{N D}=$ Not detacted

increases at the expense of the $[\mathrm{M}-\mathrm{H}]^{-}$ion current. Overall, the sum of the product ion current and the $[\mathrm{M}-\mathrm{H}]^{-}$ion current is usually above $80 \%$, indicating that few ions are lost in the CID region between the capillary and the skimmer. At higher potential differences $(>320 \mathrm{~V})$, ion transmission decreases, explaining the decrease in both product and $[\mathrm{M}-\mathrm{H}]^{-}$ion currents. These high efficiencies for CID and ion trans- 


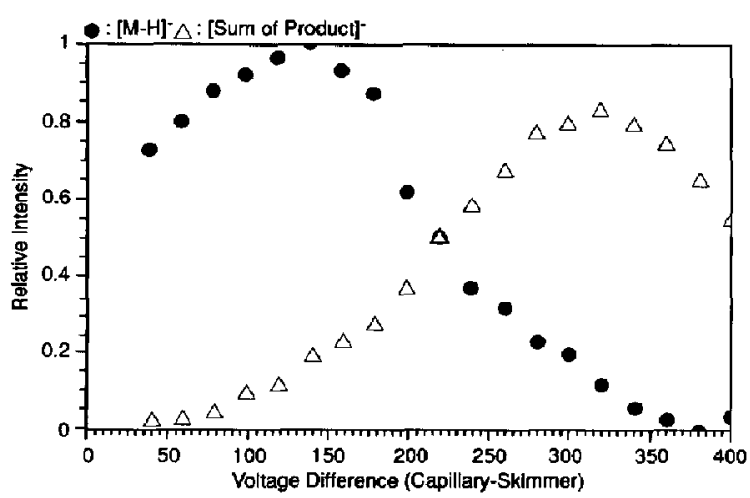

Figure 5. CID efficiency for guanosine 5 -monophosphate (MW 362 ) at various capillary/skimmer potential differences.

mission through the CID region should result in an excellent combination of sensitivity and specificity. Similar fragmentational information on nucleosides and nucleotides has been gained by fast-atom bombardment combined with tandem mass spectrometry [41-43].

ES/MS was capable of detecting low-picogram quantities of these nucleotides under negative ion selected ion monitoring detection. The $[\mathrm{M}-\mathrm{H}]^{-}$ions for the two nucleotides guanosine $3^{\prime}$-monophosphate and inosine $5^{\prime}$-monophosphate at $\mathrm{m} / z 347$ and 362 , respectively, were detected and absent from the blank at a 1-pg level. A solvent impurity exhibiting ions at $m / z \quad 311$ and 325 served to demonstrate consistent instrument operation between blank and sample analysis.

\section{Tripeptides}

Simple peptides containing a low number of amino acid residues joined covalently through peptide bonds are formed on partial hydrolysis of much longer polypeptide chains of proteins or are synthesized by chemical procedures. Because none of the $\alpha$-amino groups that are combined in peptide linkages can ionize or protonate in the $\mathrm{pH}$ range $0-14$, the acid/base behavior of peptides is contributed by the free $\alpha$-amino group of the amino terminal residue, the free $\alpha$ carboxyl group of the carboxyl terminal, and those $\mathbf{K}$ groups of the residues in intermediate positions that can ionize. Therefore, a change in $\mathrm{pH}$ can alter the net charge state of peptides and make them more accessible than the isoelectric species to positive or negative ion ES/MS detection. To investigate the ES response of tripeptides, combinations of acidic aspartic acid, which is negatively charged at $\mathrm{pH} 6-7$, were analyzed by negative ion ES/MS. Table 5 lists the relative intensity of $[\mathrm{M}-\mathrm{H}]^{-}$ions of selected symmetric tripeptides at a $\mathrm{pH}$ of 10 . Higher negative net charges tend to increase the total signal intensity in negative ion ESI. Negative ion detection is usually more sensitive for the
Table 5. Electrospray response of selected tripeptides in negative ion operation mode

\begin{tabular}{cccc}
\hline Tripeptide $^{\mathrm{a}}$ & $\begin{array}{c}\text { Net charge } \\
\text { at pH7 }\end{array}$ & $\begin{array}{c}\text { Net charge } \\
\text { at pH 10 }\end{array}$ & $\begin{array}{c}\text { Relative intensity } \\
(\%) \text { at pH 10 }\end{array}$ \\
\hline \hline DWD & -2 & -3 & 100 \\
DRD & -1 & -3 & 95 \\
WGW & 0 & -1 & 90 \\
GWG & 0 & -1 & 52 \\
WRW & +1 & -1 & 42 \\
GRG & +1 & -1 & 7 \\
RWR & +2 & -1 & 6 \\
\hline
\end{tabular}

"The tripeptides were analyzed at $250 \mathrm{pmol} / \mu \mathrm{L}$ in methanol $/$ 2-propanol /water $(1: 2: 1)$ witih $0.5 \%$ ammonium hydroxide. Capillary potential is $50 \mathrm{~V}$. $\mathrm{D}=$ aspartic acid (acid); $\mathrm{W}$ - tryptophon (neutral); $\mathrm{G}=$ glycine (neutral); $\mathrm{R}$-agrinine (basic).

acidic tripeptides, which have a net negative charge at a $\mathrm{pH}$ of 7 . On the other hand, positive ion detection was superior in sensitivity for tripeptides containing a positive net charge at a $\mathrm{pH}$ of 7 . Inconsistent behavior in sensitivity between negative and positive ion detection was observed for tripeptides with a net charge of zero at a $\mathrm{pH}$ of 7.

The tripeptides analyzed by negative ion detection ES/MS exhibited $\left[\mathrm{M}-\mathrm{H}^{-}\right.$and $[\mathrm{M}-2 \mathrm{H}]^{-2}$ ions and, on occasion, an $[\mathrm{M}-\mathrm{H}+\mathrm{IP \Lambda}]^{-}$adduct ion. At a capillary/skimmer potential difference of $50 \mathrm{~V}$, no fragmentation was observed.

\section{Explosives}

Explosives werc also evaluated for negative ion ESI because of their increasing importance in both forensic and environmental applications [44]. The analysis of postexplosive residues in debris matcrial is very important in the criminal investigation of a bombing because it can help find the link between the material used and the suspect. Several LC/MS systems have been applied to the analysis of explosives [45-49]. These systems used the split-type direct liquid introduction HPLC/mass spectrometer interface with either positive or negative chemical ionization or HPLC with off-line chemical ionization mass spectrometric detection. A more sensitive and specific technique for these special applications is thermospray HPLC mass spectrometry. It has proved useful for separating and identifying components in commercial explosives and their mixtures without interference from plasticizers, as well as for detecting explosives from hand swabs [50]. An atmospheric sampling glow discharge ion source, coupled with an ion trap mass spectrometer has also been used to detect explosives [51].

Negative ion ES/MS was evaluated for the detection of several explosives, including ammonium picrate, HMX, RDX, PETN, and tetryl. Bulky electronwithdrawing nitro groups in the neutral explosives facilitate the formation of anions in solution but also contribute to the thermal instability of the molecule. Figure 6 presents the ES mass spectrum of tetryl at a 


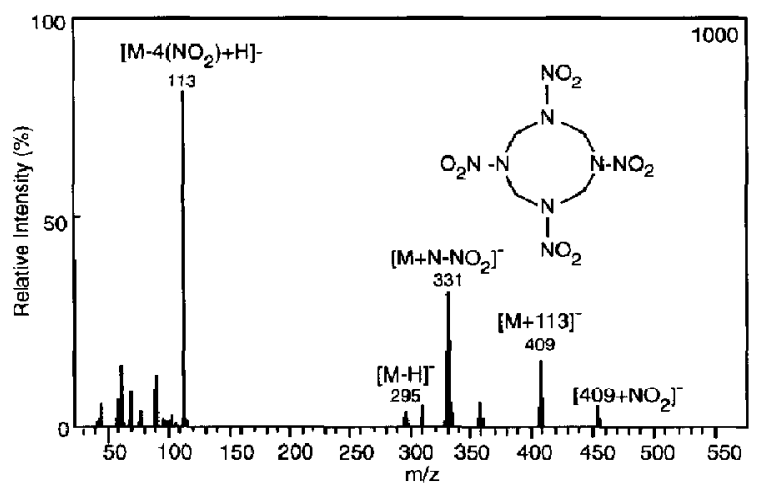

Figure 6. Negative ion ES mass spectrum of tetryl (MW 287), $170 \mathrm{fmol} / \mu \mathrm{L}$ in IPA / water $(8: 2)+1 \%(\mathrm{v} / \mathrm{v}) \mathrm{NH}_{4} \mathrm{OH}$. Number at top right indicates ion counts.

very low capillary potential of $-40 \mathrm{~V}$. Besides the $[\mathrm{M}-\mathrm{H}]^{-}$ion at $m / z 286$, a weak adduct jon [M $-\mathbf{H}$ $+\mathrm{O}]^{-}$at $m / z 302$ and various fragments, such as an $[\mathrm{M}-\mathrm{NO}]^{-}$ion at $m / z 257$, the abundant $[\mathrm{M}-2 \mathrm{NO}$ $+\mathrm{H}]^{+}$ion at $m / z 228$, and the $\left[\mathrm{M}-\mathrm{NO}-\mathrm{NO}_{2}\right]^{-}$ ion at $m / z$ 211, formed by loss of two nitro groups and addition of oxygen, were tentatively identified. The nitro groups contained in $\mathrm{HMX}$ were very unstable, and a capillary potential of $-40 \mathrm{~V}$ (Figure 7 ) produced only a very weak $[\mathbf{M}-\mathbf{H}]^{-}$ion at $m / z 295$ and an abundant $\left[\mathrm{M}-4\left(\mathrm{NO}_{2}\right)+\mathrm{H}\right]$ fragment ion at $m / z$ 113. The peak at $m / z 331$ was identified as the adduct ion $\left[\mathrm{M}+\mathrm{N}-\mathrm{NO}_{2}\right]^{-}$. The higher molecular weight adduct ions at $m / z 409$ and 455 have not been identified.

The ES mass spectrum of ionic ammonium picrate at a low capillary potential of $-40 \mathrm{~V}$ exhibits only a very intense $[\mathrm{M}]^{-}$ion at $m / z 228$. At higher capillary potentials, a consecutive cleavage of $-\mathrm{NO}_{2}$ groups formed an $\left[\mathrm{M}-\mathrm{NO}_{2}\right]^{-}$ion at $m / z$ 182, an $[\mathrm{M}-$ $\left.2\left(\mathrm{NO}_{2}\right)\right]^{-}$ion at $m / z 136$, and an $\left[\mathrm{M}-3\left(\mathrm{NO}_{2}\right)\right]^{-}$ion at $m / z 90$ (spectra not shown). Ammonium picate

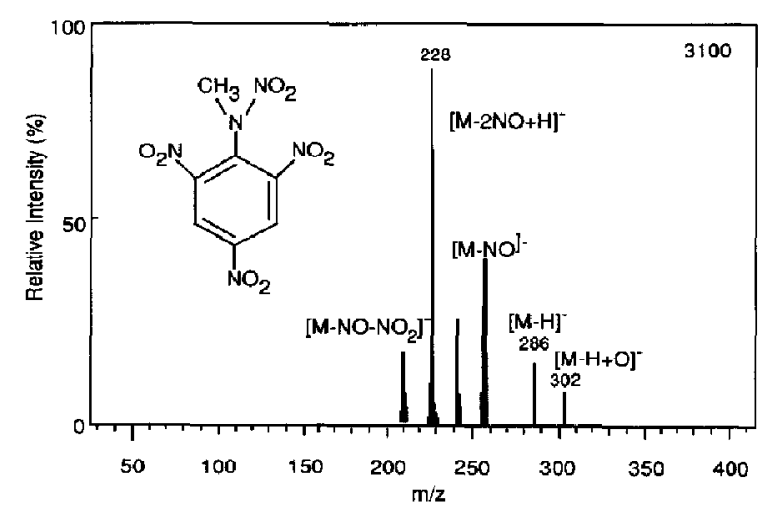

Figure 7. Negative ion ES mass spectrum of HMX (MW 296), $170 \mathrm{fmol} / \mu \mathrm{I}$. in IPA/water $(8: 2)+1 \%(\mathrm{v} / \mathrm{v}) \mathrm{NH}_{4} \mathrm{OH}$. Number at top right indicates ion counts. proved to be the most sensitive explosive by $\mathrm{ES}$, exhibiting a 10-20 times higher enhanced response compared with HMX, RDX, PETN, or tetryl. This response can be attributed to the fact that only the ammonium picrate forms enough anions in solution to produce a very intense signal in negative ion ES/MS. The other four neutral explosives showed considerably weaker signals in the $\mathrm{pH}$ range 6-10. Positive ion ES/MS was not successful in detecting these explosives.

\section{Conclusions}

Negative ion ES/MS provides a means to characterize a wide variety of compounds, such as antibiotics, synthetic drugs, nucleotides, peptides, and explosives. Conditions that promote the formation of anions in solution usually improve ES response. The appropriate choice of solvent or sheath fluid also has a substantial effect on the stability of the current produced by the ES and the intensities of the recorded signals. This can be attributed to enhancements in the nebulization and desolvation processes, resulting in higher ion evaporation yields.

Adjusting the $\mathrm{pH}$ of the solution with $0.5 \%$ to $1 \%$ $(\mathrm{v} / \mathrm{v}) \mathrm{NH}_{4} \mathrm{OH}$ increased the signal intensity in negative ion $\mathrm{ES} / \mathrm{MS}$ compared with the measurements in neutral solvents, consistent with the formation of anions in solution. Also, the addition of IPA and oxygen nebulization gas aids in the nebulization and desolvation of the solution to achieve efficient ion evaporation while effectively suppressing electric discharge. For compounds that form anions and can be nebulized and desolvated through addition of IPA and oxygen at the needle, low-picogram levels of material (e.g., nucleotides) can be detected. The amount of structurally relevant fragment ions formed by CID in the ES interface is generally lower and different from that obtained in positive ion operation. Therefore, the information gained from both operational modes helps to characterize an unknown compound or to confirm a certain tentatively proposed structure.

\section{Acknowledgments}

We thank Professor B. Erickson from the Department of Biochemistry, University of North Carolina, Chapel Hill, for the tripeptides. This research was supported in part by the U.S. Food and Drug Administration Cooperative Agreement No. FD-U-000581 and by the NIDA grant No. 5 R01 DA06315.

\section{References}

1. Micelson, D. Electrostatic Atomization; Adam Hilger; Bristol, 1990.

2. Ernbo, A. IEEE Trans. Comput, 1972, C-21, 942-948.

3. Dole, M.; Mack, L. C.; Hines, R. L.; Mobley, R. C; Ferguson, L. D.; Alice, M. B. I. Chem. Phys. 1968, 49, 2240-2249.

4. Simons, D. S.; Colby, B. N.; Evans, C. A. Jr. Int. J. Mass Spectrom. Ion Phys. 1974, 15, 291-302.

5. Yamashita, M.; Fenn, J. B. J. Phys. Chem. 1984, 88, 4451-4459. 6. Yamashita, M.; Fenn, J. B. J. Phys. Chen1. 1984, 88, 4671-4675. 
7. Whitehouse, C. M.; Dreyer, R. N., Yamashita, M.; Fenn, J. B. Anal. Chem. 1985, 57, 675-679.

8. Wong, S. F.; Meng, C. K.; Fenn, J. B. J. Phys. Chem. 1988, 92, $546-550$.

9. Fenn, J. B.; Mann, M.; Meng, C. K.; Wong, S. F. Mass Spectrom. Rev. 1990, 37-70.

10. Fenn, J. B.; Mann, M.; Meng, C. K.; Wong, S. F.; Whitehouse, C. Science 1989, 246, 64-71.

11. Whitehouse, C. M.; Shen, S.; Fenn, J. B. Presented at the 40th ASMS Conference on Mass Spectrometry and Allied Topics; Washington, DC, May 31-June 5, 1992; paper TOA 1:15.

12. Bruins, A. P.; Covey, T. R.; Henion, J. D. Anal. Chem. 1987, 59, 2642-2646.

13. Iribarne, J. V.; Thomson, B. A. J. Chem. Phys. 1976, 64, $2287-2289$.

14. Thomson, B. A.; Iribarne, J. V. I. Chem. Phys. 1979, 71, $4451-4463$.

15. Loo, J. A.; Udseth, H. R.; Smith, R. D. Rapid Commun. Mass Spectrom. 1988, 2, 207-210.

16. Wang, Y. Y.; Lyttle, M. II.; Borer, P. N. Nucleic Acids Res. 1990, 18, 3347-3352.

17. Bruins, A. P.; Weidolf, L. O. G.; Henion, J. D.; Budde, W. L. Anal. Chem. 1987, 59, 2647-2652.

18. Edlund, P. O.; Lee, E. D; Henion, J. D.; Budde, W. L. Anal. Chem. 1989, 18, 233-240.

19. Straub, R; Voyksner, R. D. J. Chromatogr. 1992, 627, 173-186.

20. Rose, M. E.; Wycherley, D.; Preece, S. W. Org. Mass Spectrom. 1992, 27, 876-882.

21. Smith, R. D.; Loo, J. A.; Edmonds, C. G.; Barinaga, C. I.; Udseth, H. R. Anal. Chem. 1990, 62, 882-899.

22. Loo, J. A.; Ogorzalek-Loo, R. R.; Light, K. J.; Edmonds, C. G.; Smith R. D. Anal. Chem. 1992, 62, 81-88.

23. Kulik, W.; Heerma, W. Biol Mass Spectrom. 1991, 20, 553-558.

24. Stults, I. T.; Marsters, J. C. Rapid Commun. Mass Spectrom. 1991, 5, 359-363.

25. Hiraoka, K; Kudaka, I. Rapid Commun. Mass Spectrom. 1992, $6,265-268$.

26. Ikonomou, M. G.; Blades, A. T.; Kebarle, P. J. Am. Soc. Mass Spectrom. 1991, 2, 497-505.

27. Chowdhury, S. K.; Katta, V.; Chait, B. T. I. Am. Chem. Soc. $1990,112,9012-9013$.

28. Cole, R. B.; Harrata, A. K. Rapid Commun. Mass Spectrom. 1992, 8, 536-539.
29. Ikonomou, M. G.; Blades, A. H.; Kebarle, P. Anal. Chem. 1990, 62, 957-967.

30. Blades, $\Lambda$. T.; Jayaweera, P.; Ikonomou, M. G.; Kebarle, $\Gamma$. J. Chem. Phys. 1990, 92, 5900-5929.

31. Smith, D. P. H. IEEE Trans. Ind. Appl. 1986, 1A-22, 527-535.

32. Hayati, 1.; Bailey, 1.; Tadros, T. F. Nature 1986, 319, 41-43.

33. Tang. L.; Kebarle, P. Anal. Chem. 1991, 63, 2709-2715.

34. Tyczkowska, K. L.; Voyksner, R. D.; Aronson, A. L. J. Chromatogr. 1991, 594, 195-201.

35. Whelton, A., Ed. The Aminoglycosides; Marcel Dekker: New York, 1982.

36. Voyksner, R. D.; Pack, T. Rapid Commun. Mass Spectrom. 1991, 5, 263-268.

37. McLaughlin, L. G.; Henion, J. D. J. Chromatogr. 1992, 591, 195-206.

38. Perkins, J. R,; Parker, C. E.; Tomer, K. B. J, Am. Soc. Mass Spectrom. 1992, 3, 139-149.

39. Straub, R. F,; Voyksner, R. D. Presented at the 40th ASMS Conference on Mass Spectrometry and Allied Topics; Washington, DC, May 31-June 5, 1992; pp 1879-1880.

40. Straub, R. F; Voyksner, R. D. Presented at the 9th (Montreux) Symposium on Liquid Chromatography Mass Spectrometry, Montreux, Switzerland, November 4-6, 1992.

41. Crow, F. W.; Tomer, K. B.; Gross, M. L.; McCloskey, J. A.; Bergstrom, D. E. Anal. Biochem. 1984, 139, 243-262.

42. Slowikowski, D. L.; Schram, K. H. Nucleosides Nucleotides 1985, 4, 309-345.

43. Tomer, K. B.; Gross, M. L.; Deinzer, M. L. Anal. Chem. 1986, $58,2527-2534$.

44. Yinon, J.; Zitrin, S. The Analysis of Explosizes; Pergamon Press: Oxford, 1981.

45. Parker, C. E.; Voyksner, R. D.; Tondeur, Y.; Henion, J. D.; Harvan, D. J.; Hass, J. R,; Yinon, J. J. Forensic Sci. 1982, 27. 495-505.

46. Yinon, J. Int. I. Mass Spectrom. Ion Phys. 1983, 48, 253-256.

47. Yinon, ].; Hwang, D. G. I. Chromalogr. 1983, 268, 45-53.

48. Vouros, P.; Petersen, B. A.; Karger, B. L.; Harris, H. Anal. Chem. 1977, 49, 1039-1044.

49. Douse, J. M. F. J. Chromatogr. 1985, 328, 155-165.

50. Voyksner, R. D; Yinon J. I. Chromatogr. 1986, 354, 393-405.

51. McLuckey, S. A.; Glish, G. L.; Asano, K. G. Anal. Chim. Acta 1989, 225, 25-35. 